\title{
Long Island Breast Cancer Study
}

National Cancer Institute

\section{Source}

National Cancer Institute. Long Island Breast Cancer Study. NCI Thesaurus. Code

C16127.

The multistudy effort to investig ate whether exposure to certain environmental factors (water quality, air pollution, electromagnetic fields, pesticides and other toxic chemicals, hazardous and municipal waste, etc.) contribute to the increased risk of breast cancer. Project started in 1993 under Public Law 103-43 and is funded and coordinated by the National Cancer Institute and the National Institute of Environmental Health Sciences. The study is conducted in Suffolk, Nassau, and Schoharie counties in New York and in Tolland County, Conn. It includes more than 10 studies: epidemiologic studies, family breast and ovarian cancer reg istry, laboratory research, and the creation of a new research tool, a Geographic Information System. 